\title{
Analysis of Monitoring, Early Warning and Emergency Response System for New Major Infectious Diseases in China and Overseas
}

\author{
Xing-li DU, Xin-rui ZHAO, Huan GAO, Wan-wan SHEN, Jia-zhi LIAO\# \\ Tongji Hospital, Tongji Medical College, Huazhong University of Science and Technology, Wuhan 430030, China
}

(C) Huazhong University of Science and Technology 2021

\begin{abstract}
Summary: In recent years, the impact of new major infectious diseases on people's normal life is becoming more and more frequent, which has brought great impact on people's life safety and social economy, especially the corona virus disease 2019, which has been sweeping the globe. Public health and disease prevention and control systems in different countries have different performances in response to the pandemic, but they all have exposed many shortcomings. Countries around the world urgently need to improve the monitoring, early warning and emergency response systems for new major infectious diseases. As the outpost and main part of medical rescue, the hospital urgently needs to establish a set of scientifically advanced emergency response mechanism that is suitable for the business process of the medical system and unified standards in order to improve the response efficiency and quality of emergency treatment.
\end{abstract}

Key words: infectious diseases; monitoring; emergency response; hospital

Infectious diseases have always been accompanied by the development of human beings. Although with the support of the continuous improvement of economic level and medical technology, human beings have preliminarily realized the prevention and control of infectious diseases ${ }^{[1]}$, due to the rapid increase and flow of global population, excessive urbanization, environmental degradation and abuse of antibiotics and other reasons, not only some major infectious diseases are resurgent, but also new major infectious diseases are emerging ${ }^{[2]}$.

The new major infectious diseases, including severe acute respiratory syndrome (SARS) in $2003^{[3-5]}$, Middle East respiratory syndrome (MERS) in 2012 $2^{[-8]}$, and corona virus disease 2019 (COVID-19) which broke out and quickly spread to the world since 2019 $9^{[9-13]}$, are susceptible to human beings because of their complex pathogen types, different transmission routes, wide spread range and fast speed, which pose a serious threat to people's health and life and cause huge losses to the social economy ${ }^{[14,15]}$.

Although great progress has been made in the construction of China's public health and disease prevention and control system, the outbreak of COVID-19 still exposes the shortcomings of China's emergency response mechanism and system construction for new major infectious diseases, such as incomplete division and cooperation mechanism

Xing-li Du, E-mail: 490086227@qq.com

\#Corresponding author, E-mail: tjglzx@tjh.tjmu.edu.cn between disease prevention and control institutions and medical institutions, "prevention and control treatment separation", insufficient medical supply and strategic reserve, etc. As the first medical security system facing new major infectious diseases, hospitals play an important role in reporting and responding to severe infectious diseases ${ }^{[16]}$, and can quickly identify and isolate potential patients.

This review summarizes the status of monitoring, early warning and emergency response system for new major infectious diseases in China and overseas, in order to provide scientific basis for the China to optimize the monitoring, early warning and response systems for new major infectious diseases, and move forward the prevention and control gate, block new major infectious diseases at an early stage.

\section{MOST COUNTRIES AROUND THE WORLD HAVE INSUFFICIENT CAPACITY TO PREVENT, DETECT AND RESPOND TO NEW MAJOR INFECTIOUS DISEASES}

In October 2019, the Johns Hopkins Bloomberg School of Public Health combined with Nuclear Threat Initiative (NTI) and Economist Intelligence Unit (EIU) launched the Global Health Security (GHS) Index, which assesses the capacity of 195 countries to cope with infectious diseases. The GHS index is mainly based on prevention (to prevent the emergence or leakage of pathogens), detection and reporting (to quickly identify and report infectious diseases that 
may cause global concern), rapid response (to quickly respond to and slow down the spread of infectious diseases), health system (to establish a robust health system, to treat patients and protect medical staff), compliance with international norms (commitment to improve the ability of countries, provide funds to repair short board of health and safety, and abide by the global relevant specification) and risk environment (overall risk environment and the vulnerability of countries to biological threats) to assess the preparedness of countries in terms of epidemic prevention. It is further divided into 34 indicators and 140 questions with a full score of 100, but the average score of all countries in the world is only 40.2, and the average score of 60 high-income countries is only $51.9^{9^{[17]}}$.

Most of the 195 countries lack the capacity of basic health systems essential for pandemic and pandemic response. According to the Findings and Recommendations Summary of GHS Index: $81 \%$ of countries score in the bottom tier for indicators related to deliberate risks (biosecurity); there is little evidence that most countries have tested important health security capacities or shown that they would be functional in a crisis, and have not allocated funding from national budgets to fill identified preparedness gaps; more than half of countries face major political and security risks that could undermine national capability to counter biological threats ${ }^{[17]}$.

From the above analysis results, it can be seen that the health security of global countries is relatively weak, and most countries in the world are not very effective in preventing epidemics of various infectious diseases, but for the emerging infectious diseases with great biosecurity threats represented by COVID-19, even no country is fully prepared ${ }^{[18]}$, every country has important weaknesses that need to be resolved and improved.

\section{STATUS OF MONITORING, EARLY WARNING AND EMERGENCY RESPONSE SYSTEM FOR NEW MAJOR INFECTIOUS DISEASES IN HIGH-INCOME COUNTRIES}

Based on the global ranking of GHS index, the top ten countries are the United States, the United Kingdom, the Netherlands, Australia, Canada, Thailand, Sweden, Denmark, South Korea and Finland. Except for Thailand, all of them are high-income countries, with the highest score of 83.5 (the United States) and the score of 68.7 for Finland in the tenth place. Policies and experience of these countries in monitoring, early warning and emergency response to new major infectious diseases are indeed valuable.

2.1 Monitoring and Early Warning System for New Major Infectious Diseases in High-income Countries

There are many kinds of infectious disease monitoring and early warning methods ${ }^{[19]}$, which can be divided into qualitative prediction and quantitative prediction according to prediction methods, as shown in fig. 1, including epidemic control chart method, ratio chart method, prediction and early warning method using "Z-D" phenomenon ${ }^{[20]}$, grey dynamic model in time series model, Box-Jenkins model and wavelet model in multi factor model ${ }^{[21]}$, etc. It is very important to select appropriate warning threshold according to epidemic characteristics and seasonal changes of infectious diseases, which can improve the performance of outbreak detection ${ }^{[22-24]}$. In recent years, monitoring and early warning methods based on big data have made rapid progress ${ }^{[25]}$. As early as 2009, American scientists used keywords obtained from Google search engine to predict influenza, and the estimated results were very close to the official surveillance data, and could predict the outbreak of influenza one to two weeks in advance ${ }^{[26]}$.

Taking the United States with the highest score as an example, relying on the big data collected from 103 large hospitals (symptom data, test data, imaging data, prescription data, genetic data, etc.), in order to find out the abnormal aggregation of diseases in time and space, and then carry out rehearsal practice in the form of joint research from the level of large medical institutions ${ }^{[27]}$. In 2006, Huang et a ${ }^{[28]}$ of Brigham Women's Hospital and Channing Laboratory of Harvard Medical School collected microbiological data of a 750-bedacademic medical center from 2002 to 2006, monitored with SaTScan information software of the World Health Organization (WHO), and identified six previously

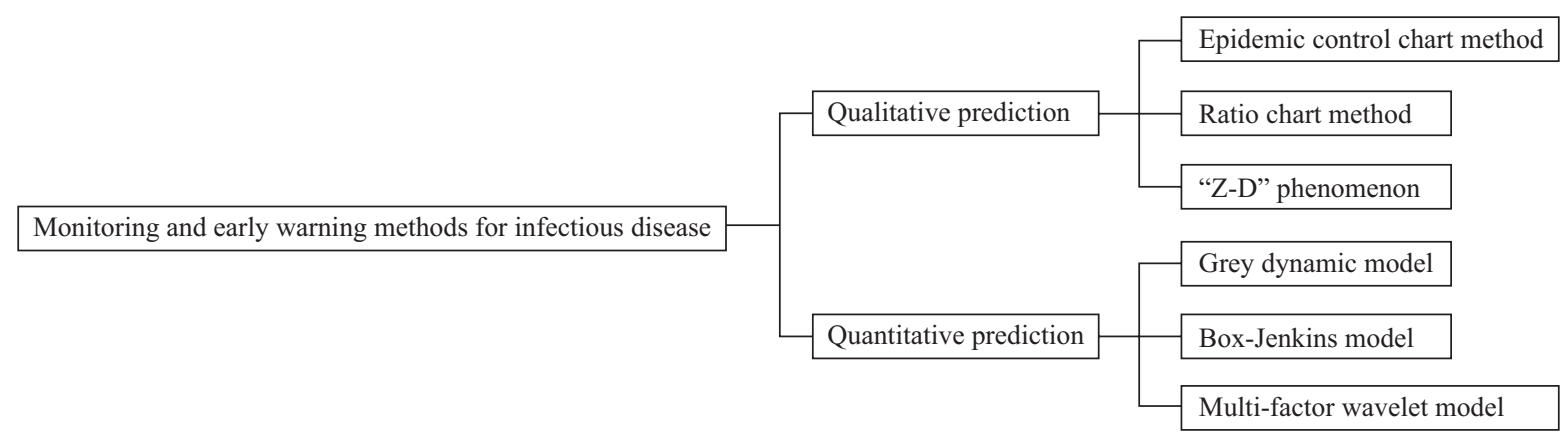

Fig. 1 Infectious disease monitoring and early warning methods 
unknown MRSAs and four VRE clusters.

The United Kingdom is the first country in the world to implement the national medical service system. The national medical service system established is the largest medical service team in Europe and praised by the WHO as one of the best medical services in the world. The response to the crisis of public health emergencies in the United Kingdom is based on the primary health care consortium and a communitycentered, bottom-up rapid response system ${ }^{[29]}$. A highly sensitive infectious disease monitoring system and early warning system have been built to detect new viruses at the first time and take timely measures.

However, although the United States and the United Kingdom are recognized as the countries with the highest health safety coefficient in the world, there are also many deficiencies ${ }^{[30,31]}$ in the fight against the COVID-19 epidemic, such as the lack of virus detection capability ${ }^{[32]}$, the lack of protective equipment ${ }^{[33,34]}$, and so on, which are the most serious problems faced by almost all countries in the early stage of the pandemic.

\subsection{Hospital Incident Command System}

The ability of many developed countries in the prevention and control of infectious diseases is also reflected at the hospital level ${ }^{[35]}$. Hospitals are the first medical security system to face newly emerging infectious diseases, and the Hospital Incident Command System (HICS) is a hospital's command system dedicated to responding to all kinds of emergencies. It can respond to emergencies within 4-7 min, and has been adopted by more than 6000 hospitals around the world ${ }^{[36,37]}$. The system is mainly composed of five functional modules: command, operation, planning, logistics and finance (table 1). These modules can be elastically scaled according to the actual situation, and some functional units can also be expanded or merged $^{[38]}$.

The above modules and their departments have clear division of labor ${ }^{[35,40]}$, and each part has clear tasks and accurate implementation ${ }^{[4]}$, which is the emergency response system adopted by hospitals in most European and American countries.

\section{STATUS OF MONITORING, EARLY WARNING AND EMERGENCY RESPONSE SYSTEM FOR NEW MAJOR INFECTIOUS DISEASES OF OTHER COUNTRIES}

Compared with the common emergency response methods of the United States and the United Kingdom, the monitoring, early warning and emergency response methods of other countries also have their own characteristics, which are mostly close to the national conditions of each country.

\subsection{Thailand}

Thailand is the only non-high-income country in the list of GHS index, ranking sixth in comprehensive ranking, with a score of 73.2. The scores in prevention, detection and reporting, rapid response and health system categories are $75.7,81,78.6$ and 70.5 respectively, while the global average score of these four items is in the range of $20-40^{[17]}$, which shows that Thailand has a sound health system and high access to medical services ${ }^{[18]}$.

In the COVID-19 epidemic, Thailand has well controlled the virus within a limited range. According to the latest epidemic released by the Ministry of Health of Thailand on April 3, 2020, 1978 cases were confirmed, with 19 deaths and 581 cured cases, showing excellent performance. Although the current number of cases in Thailand is not large, the Ministry of Public Health plans to establish a COVID-19 specialized hospital in each province $^{[42]}$. In June 2015, Thailand confirmed the first case of MERS and immediately informed the WHO. Thailand also successfully blocked the transmission of MERS in the country ${ }^{[43]}$. WHO also highly affirmed Thailand's epidemic prevention capability in the report of COVID-19 in Thailand. The report believed that Thailand has a strong ability in case discovery, risk assessment, case investigation, laboratory diagnosis,

Table 1 The five functional modules of HICS

\begin{tabular}{ll}
\hline Functional module & Working characteristics \\
\hline Command module & $\begin{array}{l}\text { The unified command structure of the command module guarantees a single and unified command system with } \\
\text { the participation of many response organizations. Everyone in the system only needs to report to the supervisor } \\
\text { of the upper level, instead of reporting the supervisor reports or under his command. } \\
\text { The actions of all personnel in the operation module must be in accordance with the established goals and other } \\
\text { important information, which means that this information needs to be shared in a timely manner, and different } \\
\text { response organizations should follow a unified action plan. } \\
\text { In the planning module system, there is a flexible plan for a certain position. Generally speaking, the number of } \\
\text { Planning module }\end{array}$ \\
$\begin{array}{l}\text { Logistics module management personnel is 3-7, which will make corresponding adjustments according to the type of events. } \\
\text { The logistics module mainly includes material security, rescue team security, information technology security, } \\
\text { etc., to ensure that public health emergencies anywhere, get first-aid medicines within } 12 \mathrm{~h}{ }^{[39]} \text {. And the Hospital } \\
\text { Information Management Association's powerful electronic information system can timely update the data of } \\
\text { the patient, and real-time monitoring of transshipment process has greatly improve emergency efficiency. } \\
\text { The financial department guarantees the timely availability of medical emergency rescue funds through } \\
\text { disaster insurance and special emergency funds }{ }^{[36]} \text {. }\end{array}$ \\
Financial module
\end{tabular}


clinical management, infection prevention and control, and risk communication.

Thailand has a rapid response system, a strong epidemiological training program and a national laboratory system. Any epidemic infectious disease will trigger the rapid response system automatically once it appears, and the system will take standardized measures to deal with the sudden infectious disease according to the rules. In response to COVID-19, novel coronavirus detection can be carried out in 44 laboratories throughout Thailand, including public institutions, private institutions and foreign cooperative institutions, with very high detection efficiency ${ }^{[44]}$. At the same time, the relevant epidemic resistance pattern in Singapore is similar to that in Thailand ${ }^{[45]}$.

\subsection{Japan}

Japan has established a relatively complete emergency management organization system for public emergencies. The law stipulates that all prefectures and counties must set up more than one backbone disaster medical rescue center and several necessary regional disaster medical rescue centers. Once a disaster occurs, it will immediately start to become a designated hospital for emergency treatment, to accommodate the injured and sick in the disaster to the greatest extent ${ }^{[20]}$. Hospitals are divided into three levels, which respectively accept and treat mild, moderate and severe patients, and strive to establish an emergency collaborative relationship network between regional and inter-regional hospitals ${ }^{[46]}$. All organizations and personnel are clear about their tasks and can strictly abide by the relevant emergency management laws ${ }^{[46]}$.

\subsection{Iran}

Based on the HICS commonly adopted by European and American countries, many other countries have also established their own emergency systems according to their own national conditions. For example, in 2013, in order to optimize the disaster management of hospitals in Iran, the HICS process (2006 version) commonly used in European and American countries was modified based on its national conditions. The revised parts are mainly concentrated on: (1) The quality control officer is added to the command group; (2) Security is defined as a new part; (3) The infrastructure and business continuity branches are transferred from the business section to the logistics section and the administration section respectively; (4) The Planning Section is merged into the Finance/ Administration section. This new model can improve the performance of hospitals in disaster management. During the simulated and actual disasters, other studies are needed to test the feasibility and effectiveness of the improved HICS in Iran. This process may be a useful model for other countries that want to improve their hospital's disaster incident management system ${ }^{[47]}$.
4 STATUS OF MONITORING, EARLY WARNING AND EMERGENCY RESPONSE SYSTEM FOR NEW MAJOR INFECTIOUS DISEASES IN CHINA

\subsection{Application Status of China Infectious Disease Automated-alert and Response System}

Before the outbreak of SARS, the Chinese Centers for Disease Control (CDC) established a mobile percentile method to detect the outbreaks and epidemics of infectious diseases. After years of research, the China Infectious Disease Automated-alert and Response System (CIDARS) was developed and completed in April 2008, and was used to strengthen the monitoring and supervision of infectious diseases ${ }^{[22,48]}$. The system mainly adopts fixed threshold method for anomaly detection. The workflow was divided into three steps: early warning signal sending, preliminary verification of early warning signal and on-site investigation confirmation.

In 2016, Zhang et al ${ }^{[49]}$ found that the early warning system can stably automatically calculate the infectious diseases report date and generate early warning signals in a timely manner. The signal response rate and response timeliness are good, but the proportion of suspected signals is low. The early warning system can further improve the detection effect by distinguishing areas with different incidence levels of the disease and different epidemic seasons, exploring new sources of early warning date, and narrowing the space detection range. Chinese surveillance personnels have successfully found the increase of cases in Hotan area of Xinjiang through the active surveillance system for acute paralysis cases, and confirmed by the laboratory that the cases are transmitted by imported poliovirus from Pakistan ${ }^{[50]}$.

\subsection{Monitoring and Early Warning System for New Major Infectious Diseases in China}

China ranks 51st in the GHS index and 4th in the five East Asian countries. The scores/rank of prevention, detection and notification, rapid response, medical system, compliance with international norms and environmental risk are 45.0/50, 48.5/64, 48.6/47, $45.7 / 30,40.3 / 141$ and $64.4 / 58$ respectively, with a total score of $48.2^{[17]}$. In addition to the category of compliance with international norms, the scores of other categories are higher than the average scores of 159 countries.

In response to the COVID-19 pandemic, China has taken the most comprehensive, strict, and thorough prevention and control measures, unprecedented large-scale isolation measures, and unprecedented deployment of national resources for large-scale medical treatment. After arduous efforts, China paid a huge price and sacrifice, and effectively reversed the situation of the epidemic ${ }^{[51]}$. With the correct leadership of the Party Central Committee and the joint 
efforts of the people across the country, the domestic epidemic situation has been effectively controlled, but the shortcomings and deficiencies exposed therein still need to be considered. It is urgent to improve monitoring, early warning and emergency response system for new major infectious diseases, build an effective monitoring and early warning network for new major infectious diseases, and move forward the prevention and control gate.

China emergency management system still has many shortcomings: (1) The organizational system is not perfect ${ }^{[52]}$, such as general hospitals do not set up health emergency management departments independently ${ }^{[33]}$, lack of comprehensive coordination and command institutions and information management centers, etc., and the current "segmented" emergency management mode lacks effective coordination and cooperation mechanism and recovery mechanism ${ }^{[23]}$. (2) The emergency plan and implementation evaluation are not perfect, there is a tendency of "preplanning", there is a lack of emergency drill and objective evaluation, and the emergency response capacity of new major infectious diseases is not strong ${ }^{[54]}$. (3) The support system is relatively backward, there is no prior funding support system $^{[55]}$, the provision of professional personnel and emergency material resources is inconsistent with the implementation of emergency tasks, the information system sharing system between hospitals and departments of disease control, transportation, public security and other departments is not perfect; The information release and public opinion guidance need to be strengthened ${ }^{[56]}$. (4) Other weak links, such as the definition of responsibility system function of medical institutions in the emergency process, the research and development of new drugs and new equipment, the weak foundation of information support ${ }^{[57]}$, the lack of clear key elements and tasks of information integration and efficient utilization, the upgrading of hospital infection control, and the lack of corresponding task list and model guidance for emergency support of materials.

\section{CONCLUSION}

Due to the characteristics of new major infectious diseases, such as sudden, complex, urgent, strong spread and great harm, the monitoring ability and emergency response system of global response to new major infectious diseases are not perfect at present, especially in the current "big test" of response to the COVID-19 epidemic, most countries have failed to submit a satisfactory answer sheet, proving that the global response to new epidemic situation is not perfect. There is much room for improvement in the monitoring and emergency response system.

As the outpost and the main part of medical aid, the hospital is not only the most sensitive first line at the beginning of the epidemic, but also performs the most important rescue task in the epidemic "fight" [58]. It is urgent to establish a set of scientific and advanced emergency response mechanism which is suitable for the business process of medical system and unified standards, so as to improve the response efficiency and quality of emergency response.

\section{Conflict of Interest Statement}

The authors declare that they have no conflict of interest.

\section{REFERENCES}

1 Choi EK, Lee JK. Changes of global infectious disease governance in 2000s: Rise of Global Health Security and Transformation of Infectious Disease Control System in South Korea. Uisahak, 2016,25(3):489-518

2 World Health Organization. The world health report 2007-A safer future: global public health security in the 21 st century. https://www.who.int/whr/2007/en/:2007

3 Griffiths S, Lau J. The influence of SARS on perceptions of risk and reality. J Public Health (Oxf), 2009,31(4): 466-467

4 Zhong NS, Zheng BJ, Li YM, et al. Epidemiology and cause of severe acute respiratory syndrome (SARS) in Guangdong, People's Republic of China, in February, 2003. Lancet, 2003,362(9393):1353-1358

5 Ksiazek TG, Erdman D, Goldsmith CS, et al. A novel coronavirus associated with severe acute respiratory syndrome. N Engl J Med, 2003,348(20):1953-1966

6 Drosten C. Is MERS another SARS?. Lancet Infect Dis, 2013,13(9):727-728

7 Rasmussen SA, Gerber SI, Swerdlow DL. Middle East respiratory syndrome coronavirus: update for clinicians. Clin Infect Dis, 2015,60(11):1686-1689

8 Rha B, Rudd J, Feikin D, et al. Update on the epidemiology of Middle East respiratory syndrome coronavirus (MERS-CoV) infection, and guidance for the public, clinicians, and public health authorities January 2015. MMWR Morb Mortal Wkly Rep, 2015, 64(3):61-62

9 Gao Y, Qiu HB, Zhou S, et al. Accumulated clinical experiences from successful treatment of 1377 severe and critically Ill COVID-19 cases. Curr Med Sci, 2020,40(4):597-601

10 Rothe C, Schunk M, Sothmann P, et al. Transmission of 2019-nCoV infection from an asymptomatic contact in Germany. N Engl J Med, 2020,382(10):970-971

11 Shim E, Tariq A, Choi W, et al. Transmission potential and severity of COVID-19 in South Korea. Int J Infect Dis, 2020,93:339-344

12 Shirato K, Nao N, Katano H, et al. Development of genetic diagnostic methods for novel coronavirus 2019 (nCoV-2019) in Japan. Jpn J Infect Dis, 2020,73(4):30430713

13 Hu HT, Xu S, Wang J, et al. Respiratory Support in Severely or Critically Ill ICU Patients With COVID-19 in Wuhan, China. Curr Med Sci, 2020,40(4):636-641

14 Adams JG, Walls RM. Supporting the health care workforce during the COVID-19 global epidemic. 
JAMA, 2020,323(15):1439-1440

15 Shimizu K. 2019-nCoV, fake news, and racism. Lancet, 2020,395(10225):685-686

16 Zeng J, Huang J, Pan L. How to balance acute myocardial infarction and COVID-19: the protocols from Sichuan Provincial People's Hospital. Intensive Care Med, 2020,46(6):1111-1113

172019 Global Health Security Index. (2019) [2020-0411]. https://www.ghsindex.org/

18 Ma L. "Global health and safety index" and epidemic response capacity of different countries [EB/OL]. (2020-02-18) [2020-04-11]. http://baijiahao.baidu.com/ $\mathrm{s} ? \mathrm{id}=1658861001936489262 \& \mathrm{wfr}=$ spider $\&$ for $=\mathrm{pc}$

19 Guo FQ, Yang KQ, Zhao LT, et al. Construction of management platform for the prevention and control of corona virus disease 2019 based on "Internet+". Chin Nurs Res (Chinese), 2020,34(5):753-755

20 Yang WZ, Xing HX, Wang HZ, et al. A study on early detection for seven infections diseases. Chin J Epidemiol (Chinese), 2004,25(12):37-39

21 Capan M, Hoover S, Jackson EV, et al. Time series analysis for forecasting hospital census: application to the neonatal intensive care unit. Appl Clin Inform, 2016,7(2):275-289

22 Wang R, Jiang Y, Michael E, et al. How to select a proper early warning threshold to detect infectious disease outbreaks based on the China infectious disease automated alert and response system (CIDARS). BMC Public Health, 2017,17(1):570

23 Wang RP, Jiang YG, Zhao GM, et al. "Outbreak Gold Standard" selection to provide optimized threshold for infectious diseases early-alert based on China Infectious Disease Automated-alert and Response System. Curr Med Sci, 2017,37(6):833-841

24 Wang R, Jiang Y, Guo X, et al. Influence of infectious disease seasonality on the performance of the outbreak detection algorithm in the China Infectious Disease Automated-alert and Response System. J Int Med Res, 2018,46(1):98-106

25 Qu XH, Yuan W, Yuan W, et al. Application of spatiotemporal big data analysis technologies in forecasting and early warning of infectious diseases. Chin Digit Med (Chinese), 2015,10(08):36-39

26 Ginsberg J, Mohebbi MH, Patel RS, et al. Detecting influenza epidemics using search engine query data. Nature, 2009,457(7232):1012-1014

27 Foote MMK, Styles TS, Quinn C. Assessment of hospital emergency department response to potentially infectious diseases using unannounced mystery patient drills --- New York City, 2016. MMWR Morb Mortal Wkly Rep, 2017,66(36):945-949

28 Huang SS, Yokoe DS, Stelling J, et al. Automated detection of infectious disease outbreaks in hospitals: a retrospective cohort study. PLoS Med, 2010,7(2): e1000238

29 Keramarou M, Evans MR. Completeness of infectious disease notification in the United Kingdom: A systematic review. J Infect, 2012,64(6):555-564.

30 Adalja AA, Toner E, Inglesby TV. Priorities for the US health community responding to COVID-19. JAMA, 323(14):1343-1344

31 Mahase E. COVID-19: UK holds off closing schools and restricts testing to people in hospital. BMJ, 2020,368: m1060

32 Amrane S, Tissot-Dupont H, Doudier B, et al. Rapid viral diagnosis and ambulatory management of suspected COVID-19 cases presenting at the infectious diseases referral hospital in Marseille, France, - January 31st to March 1st, 2020: A respiratory virus snapshot. Travel Med Infect Dis, 2020,36:101632

33 Chughtai AA, Seale H, Islam MS, et al. Policies on the use of respiratory protection for hospital health workers to protect from coronavirus disease (COVID-19). Int J Nurs Stud, 2020,105:103567

34 Rimmer A. COVID-19: GPs call for same personal protective equipment as hospital doctors. BMJ, 2020, 368:m1055

35 Adini B, Goldberg A, Laor D, et al. Assessing levels of hospital emergency preparedness. Prehosp Disaster Med, 2006,21(6):451-457

36 Bahrami P, Ardalan A, Nejati A, et al. Factors affecting the effectiveness of hospital incident command system; findings from a systematic review. Bull Emerg Trauma, 2020,8(2):62-76

37 Joint Commission on Accreditation of Healthcare Organizations. Approved: revisions to emergency management standards for critical access hospitals, hospitals, and long-term care. Revisions to Emergency Management Standards EC.4.10 and EC.4.20. Jt Comm Perspect, 2007,27(6):1,3-10

38 Wang HK, Sun TT, Zheng CY. Enlightenment of American hospitals incident command system (HICS). Chin J Emerg Resusc Disast Med (Chinese), 2012,7(7): 604-607

39 Murray RM, Davis AL, Shepler LJ, et al. A systematic review of workplace violence against emergency medical services responders. New Solut, 2020,29(4): 487-503

40 Hospital Incident Command System. 2014 HICS Revision. (2014) [2020-04-11]. http://www. emsa. ca. gov//disaster medical services division hospital incident command system resources

41 Shooshtari S, Tofighi S, Abbasi S. Benefits, barriers, and limitations on the use of Hospital Incident Command System. J Res Med Sci, 2017,22:36

42 Hospitals in every province. (2020) [2020-04-09] https://pr.moph.go.th/?url=pr/detail/2/04/140888/

43 Plipat $\mathrm{T}$, Buathong $\mathrm{R}$, Wacharapluesadee $\mathrm{S}$, et al. Imported case of Middle East respiratory syndrome coronavirus (MERS-CoV) infection from Oman to Thailand, June 2015. Euro Surveill, 2017,22(33):30598

44 Sookaromdee P, Wiwanitkit V. Imported novel coronavirus infections: observation on active and passive case detection in Thailand. [published online ahead of print, 2020 Mar 2]. Popul Health Manag, 2020, doi:10.1089/pop.2020.0014

45 Wong J, Goh QY, Tan Z, et al. Preparing for a COVID-19 pandemic: a review of operating room outbreak response measures in a large tertiary hospital in Singapore. Can J Anaesth, 2020,67(6):732-745

46 Morikane K. Infection control in healthcare settings in Japan. J Epidemiol, 2012,22(2):86-90

47 Djalali A, Hosseinijenab V, Peyravi M, et al. The hospital incident command system: modified model 
for hospitals in Iran. PLoS Curr, 2015, 7. doi:10.1371/ currents.dis.45d66b5258f79c1678c6728dd920451a

48 Yang WZ, Lan YJ, Li ZJ, et al. The application of national outbreak automatic detection and response system, China. Chin J Epidemiol (Chinese), 2010,31(11):12401244

49 Zhang HL, Zeng LJ, Lai SJ, et al. Performance of China infectious disease automated-alert and response system in 2016. Dis Surveillance (Chinese), 2018,33(02):159167

50 Luo HM, Zhang Y, Wang XQ, et al. Identification and control of a poliomyelitis outbreak in Xinjiang, China. N Engl J Med, 2013,369(21):1981-1990

51 The State Council Information Office of the People's Republic of China. Fighting COVID-19: China in Action. (2020-06-07)[2020-06-21]. http://www.scio.gov.cn/ztk/ dtzt/42313/43142/index.htm.

52 Cao Y, Li Q, Chen J, et al. Hospital emergency management plan during the COVID-19 epidemic. Acad Emerg Med, 2020,27(4):309-311

53 Zhang J, Wang YD, Wang ML. Problems and suggestions in the health emergency system of Beijing. Chin J Emerg
Resusc Disast Med (Chinese), 2016,11(8):840-842

54 Cai HB, Gong SW. Comparative study of evaluation system of hospital emergency drill between China and the United States. Med Soc (Chinese), 2017,30(3):1921

55 Liao JZ, Wu J. Development path and urgency of further strengthening construction of public hospitals based on novel coronavirus pneumonia treatment. Curr Med Sci, 2020,40(2):290-294

56 Wang J, Yuan B, Li Z, et al. Evaluation of public health emergency management in China: a systematic review. Int J Environ Res Public Health, 2019,16(18):3478

57 Wang MH, Chen HK, Hsu MH, et al. Cloud computing for infectious disease surveillance and control: development and evaluation of a hospital automated laboratory reporting system. J Med Internet Res, 2018, 20(8):e10886

58 Lee IK, Wang CC, Lin MC, et al. Effective strategies to prevent coronavirus disease-2019 (COVID-19) outbreak in hospital. J Hosp Infect, 2020,105(1):102103

(Received May 19, 2020; accepted June 25, 2020) 